\author{
Е.П. Бережная \\ Государственная публичная научно-техническая \\ библиотека СО РАН, Новосибирск
}

\title{
Пушкинология Тынянова
}

Аннотащия: В итоговой статье «Пушкин» Тынянов указал на двупланность пушкинской семантики как на основной фактор литературной эволюции поэта («катастрофической по силе и быстроте»). Семантическая двупланность продуцирует «колеблющиеся» смыслы и поэтому может выступать как бы регулятором «противоречивого осмысления Пушкина со стороны современников и позднейших литературных поколений». В этом контексте важно отметить интерес Тынянова к «высокой оде», имеющей двойственную, двупланную природу. Формалистические установки Тынянова исключали, с одной стороны, продуктивность психологического подхода к описанию литературных явлений; с другой - создавали необходимые условия для построения поэтики, т. е. теоретически обоснованной модели литературной науки.

In his final paper «Pushkin» Tynyanov has pointed out the two-sidedness of Pushkin's semantics as a major factor of the poet's literary evolution («of catastrophic force and speed»). The semantic two-sidedness produces «varying» meanings and hence can act as a kind of regulator of contradictory comprehension of Pushkin by his contemporaries and subsequent literary generations. In this context, it is important to note Tynyanov's interest in «a high ode», having a dual, two-sided nature. Tynyanov's formalistic orientations excluded, on the one hand, the efficiency of psychological approach to the description of literary phenomena; on the other - provided the necessary conditions for creating poetic forms, i. e. theoretically substantiated literary models.

Ключевые слова: Пушкин, «Руслан и Людмила», «Евгений Онегин», онегинская строфа, семантическая двупланность, «колеблющиеся» смыслы, динамика литературных форм.

Pushkin, «Ruslan and Lyudmila», «Eugene Onegin», Onegin's stanza, semantic two-sidedness, «varying» meanings, dynamics of literary forms.

УДК: $82.0+882.08$.

Контактная информация: Новосибирск, пр. Лаврентьева, 6. ГПНТБ СО РАН. Тел. (383) 3301760. E-mail: bereg.63@mail.ru.

Основу онегинских штудий Тынянова 1920-х годов определял резко отрицательный подход к мифологизированному прочтению Пушкина, «абсолютность» которого была заявлена в философско-критических статьях Ап. Григорьева, Ф. Достоевского, Н. Страхова, в идеалистических воззрениях символистов начала века. В статье «Мнимый Пушкин» (1922) Тынянов писал: «“Пушкин - это наше все”. Эта старая формула Аполлона Григорьева, еще подкрепленная в эпоху символизма религиозно-философской абстракцией Мережковского, остается и до сих пор некоторым знаменем. Опираясь на ценность Пушкина, эту ценность объявили единственной: примите Пушкина, остальное приложится. Пока это остается в области философствований на литературные темы, где литература, очевидно для всех, является объектом игры, а не изучения, формула никаких последствий за 
собой не влечет.. < ..> Гораздо важнее, что формула эта находит прочную жизнь в недрах самой литературной науки. Рядом с наукою о литературе незаметно и постепенно выросла “наука о Пушкине”... <..> Как бы высока ни была ценность Пушкина, ее все же незачем считать исключительной. Незачем смотреть на всю предшествующую литературу как на подготовляющую Пушкина (и в значительной мере им отмененную), а на всю последующую как на продолжающую его (или борющуюся с ним). Этот наивный телеологизм ведет к полному смещению исторического зрения: вся литература под знаком Пушкина становится бессмысленной, а сам он остается непонятным “чудом”» [Тынянов, 1977, с. 78]. В 1925 году, подводя итог историко-литературному и теоретическому изучению творчества поэта, Б. Томашевский резюмировал: «В общем для литературы последних лет характерен сдвиг от “абсолютного” Пушкина к сравнительно-историческому его изучению. До сих пор типичен был подход к Пушкинским произведениям, как к некоторым непреходящим, безотносительным ценностям, требующим исторической перспективы лишь в качестве некоторого второстепенного корректива; за последнее время внимание обращено на историческую роль Пушкина, на изучение его в среде литературных традиций его времени, и с точки зрения интересов его эпохи. Момент исторический выступает на первый план, момент безотносительно эстетический уступает ему свое место» [Томашевский, 1925, с. 90-91].

Пафос открытия, присущий научным поискам Тынянова, подкреплялся принципиальным требованием формалистической поэтики - «вдвинуть Пушкина в исторический ряд и изучать его так же, как и всякого рядового деятеля литературы» [Там же, с. 74-75]. Еще в «Архаистах...» Тыняновым была выстроена модель стиховой культуры Пушкина, взаимосвязанной с младоархаистической литературной теорией, и был выведен тезис о Пушкине как наследнике и «завершителе» классицистической поэтики в области жанровых и стилевых модификаций: «Пушкин не только завершитель в области художественной литературы: в той же мере он завершает и теоретическую литературную мысль XVIII века; его произведениям предшествуют долгие литературные изучения (“Борис Годунов”), и всегда они являются разрешением теоретических задач. С концом его деятельности обрывается не только поэтическая, но и теоретическая традиция младшей ветви XVIII века, уступая место традиции русских романтиков 20 -х годов, к которой Пушкин относится враждебно и подозрительно» [Тынянов, 1977, с. 415].

Новаторство Тынянова в «Архаистах и Пушкине» заключалось прежде всего в отказе от дихотомической модели «романтизм-классицизм» применительно к литературному процессу 10-20-х гг. девятнадцатого века. Более привычное описание русской литературы 1820 -х годов в терминах романтизма и классицизма указывало бы на выстраивание модели литературного текста через внетекстовую соотнесенность. Такое отождествление уровней литературного ряда с внелитературными рядами Тыняновым решительно отвергалось: «Подходя с готовыми критериями “классицизма" и “романтизма” к явлениям тогдашней русской литературы, мы прилагаем к многообразным и сложным явлениям неопределенный ключ, и в результате возникает растерянность, жажда свести многообразное явление хоть к каким-нибудь, хоть к кажущимся простоте и единству» [Тынянов, 1969, c. 51]. В русской литературе, согласно тыняновской схеме, обнаруживалось более дробное деление, связанное с различием литературных установок в отношении поэтического языка, стиля и жанров. Нарисованная Тыняновым картина литературной борьбы так называемых «архаистов» и «новаторов» была борьбой за «направление поэтического слова»: с одной стороны, эмоционально-убедительное слово «высокой оды» с установкой на имманентное звучание, с другой, логически-ясное слово «легкой поэзии», где важную роль играет принцип «семантической точности». Проводимое в «Архаистах...» разделение разных рядов культуры имело целью показать общность литературно-теоретических оценок там, где принципиально несоединимыми оставались общественно-политические позиции. 
При условии такого сложного взаимодействия становилась очевидной эволюционная динамическая природа литературного факта и, вместе с тем, подтверждался один из главных принципов литературного развития - «не планомерная эволющия, а скачок, не развитие, а смещчение» [Тынянов, 1977, с. 256]. «Литература идет многими путями одновременно - и одновременно завязываются многие узлы. Она не поезд, который приходит на место назначения...». «Чем непогрешимее логика в применении к таким вещам, которые движутся, - а литература такая вещь - чем она прямолинейнее, правильнее, тем она оказывается менее права» [Там же, c. 166,182$]$.

Отменив основную схему «романтизм-классицизм» применительно к русской литературе ${ }^{1}$, Тынянов совершенно особым образом актуализировал вопрос о позиции Пушкина в литературном движении первой четверти девятнадцатого века: «В борьбе литературных “сект” Пушкин занимает исторически оправданное место беспартийного... <..> Пушкин был в литературе “скептик” и использовал элементы враждебных течений... <..> Подобно тому как в отношении языка Пушкин дал новые достижения, потому что не замыкался в “сектантство” Вяземского или Кюхельбекера, а соединял принципы и достижения противоположных школ, подобно этому и тематический строй был ценен для него, главным образом, своим разнообразием и противоречивою спайкой высокого и низкого, стилистически приравненных, доставляющих материал для колебания двух планов» [Тынянов, 1969, с. 71, 116-117]. Тынянову оказалось достаточно сложно вместить концепцию эволюционного пути Пушкина в литературную культуру 1820-х годов. Двойственная, двупланная природа пушкинского слова становилась основным фактором литературной эволюции поэта, «катастрофической по силе и быстроте», и она же была как бы регулятором «противоречивого осмысления его творчества со стороны современников и позднейших литературных поколений» [Там же, с. 122]. Признав особое положение Пушкина в литературе девятнадцатого века, Тынянов «отказывается судить» о природе пушкинского творчества, предполагая в самом его творчестве особые основы для разноречивых оценок. «Самая природа оценок, доходящая до того, что любое литературное поколение либо борется с Пушкиным, либо зачисляет его в свои ряды по какому-либо одному признаку, либо, наконец, пройдя вначале первый этап, кончает последним, - предполагает особые основы для этого в самом его творчестве» [Там же, с. 122].

В итоговой статье «Пушкин» (1928) Тынянов указал на двупланность пушкинской семантики как на основной фактор литературной эволюции поэта. «Это колебание, это постоянное переключение из одного плана в другой (ср. хотя бы с р а в н е н и я у Пушкина, вовсе не несущие функции уподобления, а служащие именно для внесения другого плана - примеры: петух, “султан курятника” во II песне "Руслана и Людмилы", кот и мышь в "Графе Нулине”, волк в XIII строфе I главы “Онегина" и т. д.), это переключение является сильным динамизирующим средством, дающим возможность Пушкину создать новый эпос, новую большую форму» [Там же, с. 117] (разрядка Тынянова - Е.Б.). Большая эпическая форма была заявлена в первой поэме Пушкина «Руслан и Людмила», отозвавшейся в «Евгении Онегине» жанрово-стилистическими и сюжетно-композиционными явлениями.

Обратимся к произведенному Тыняновым истолкованию пушкинской поэмы, поскольку вне понимания ее не может быть вполне осознан пушкинский стихо-

1 «...Литературные деятели 20-х годов иногда тщательно гнались за неуловимыми понятиями классицизма и романтизма... < ..> Происходило это, во-первых, вследствие того, что у нас "готовые" (на деле, конечно, тоже не готовые, а упрощенные) западные формулы прикладывались к сложным национальным явлениям и в них не умещались. Кроме того, западные течения, запаздывая, совмещались в русской литературной теории» [Тынянов, 1969, с. 52-53]. 
вой элос. Прежде напомним, что в литературном движении 1810-1820-х годов, согласно Тынянову, доминировала борьба архаистов за «большую стиховую форму». Важно отметить интерес архаистов к метрическим и строфическим формам, связанный с вопросом о высоких жанрах. Полемика вокруг метра (гекзаметра), единственно пригодного для большой эпической формы, «...захватила широкие литературные круги и надолго поставила вопрос о русском гекзаметре в число наиболее важных литературных вопросов» [Там же, с. 33]. Обоснованное оживление вызвала и дискуссия об эпической строфе (октаве). Возникающее в этой связи соотношение функции и формального элемента Тынянов устанавливает следующим образом: «Страстность споров вокруг невинной с виду октавы под стать трагическому сиротству функции без формы» [Тынянов, 1977, с. 276]. Тынянову необходимо подчеркнуть функциональный аспект проблемы и, тем самым, заявить об имманентной, формообразующей (а не общественной) литературности архаистов: «Архаистическая литературная теория была вовсе не необходимо связана с реакцией александровского времени... <..> Борьба за высокие жанры, с одной стороны, за просторечие против маньеризма - с другой, могла сочетаться с борьбой против изящной, но небольшой “литературы для немногих” $[$ Тынянов, 1969, c. 35].

Шишковисты (или так называемые «старшие архаисты») перенесли теорию литературного языка в область языковой рефлексии; карамзинисты противопоставили отношению к поэтическому слову стилистическое различие. По отношению к поэтическим жанрам и шишковистами, и карамзинистами подчеркивалось принципиальное различие позиций. С одной стороны, культ «мелких», внелитературных жанров, основанных на «игре стилистическими мелочами»; с другой требование большой стиховой формы, высокого стиля и просторечия.

Большая стиховая форма архаистам не удается, так как и архаистическая, и карамзинистская литературные теории утверждали принцип замкнутой классификации жанров, отношение к которым осознается в виде «готовых вещей» (ср.: «Мы все еще сохраняем отношение к жанрам как к готовым вещам. Поэт встает с места, открывает какой-то шкаф и достает оттуда тот жанр, который ему нужен. Каждый поэт может открыть этот шкаф. И мало ли этих жанров, начиная с оды и кончая поэмой. Должно обязательно хватить на всех. Но промежуток учит другому. Потому он и промежуток, что нет готовых жанров, что они создаются и медленно, и анархически, не для общего употребления») [Тынянов, 1977, c. 191].

Подчеркиваемый Тыняновым в его теоретических построениях тезис о динамической природе стихового слова в особом смысле актуализировал вопрос о становлении устойчивого жанрового канона. Жанр создается тогда, когда у стихового слова есть все качества, необходимые для того, чтобы, «усилясь и доводясь до конца», дать замкнутый вид [Там же, с. 191]. Осознание поэтом «качества своего слова» приводит его к жанру. «В “Евгении Онегине” вы видите, как своеобразие стихового слова проещируется в жанр, как бы само создает его. Незачем говорить, что это качество стихового слова, которое, сгущаясь, осознаваясь, ведет к жанру, не в метре, не в рифме, а в том смысловом своеобразии слова, которым оно живет в стихе» [Там же]. Основные жанровые и структурные характеристики пушкинского стихотворного романа определились в поэме «Руслан и Людмила», в которой стиховое слово развертывалось по законам, противоречащим статическому определению жанра ${ }^{1}$. «Слово стало заменять у Пушкина своею ассоциатив-

\footnotetext{
${ }^{1}$ Ср. из статьи Ю.Н. Тынянова «Литературный факт»: «Попробуем, например, дать определение понятия поэма, т. е. понятия жанра. Все попытки единого статического определения не удаются. Стоит только взглянуть на русскую литературу, чтобы в этом убедиться. Вся революционная суть пушкинской “поэмы” "Руслан и Людмила" была в том, что это была “не-поэма" (то же и с “Кавказским пленником”)» [Тынянов, 1977, с. 255].
} 
ною силою развитое и длинное описание. <..> Это отношение к слову не как к знаку предмета, а как к знаку слова, вызывающему ассоциативные лексические ряды, делает слово у Пушкина двупланным. < ..> Слово не имеет поэтому у Пушкина одного предметного значения, а является как бы колебанием между двумя и многими. Оно многосмысленно» [Тынянов, 1969, с. 131, 133] ${ }^{1}$.

Выбор фабульного материала сказки, а также ориентация на «читательницу» Карамзина, заявленная в «Посвящении» поэмы:

\section{Для вас, души моей царицы, \\ Красавицы, для вас одних... \\ Счастлив уж я надеждой сладкой, \\ Что дева с трепетом любви \\ Посмотрит, может быть, украдкой \\ На песни грешные мои, -}

были вполне оправданы в пушкинское время. Необычной была не та или иная декларируемая «автором» литературная позиция, но совершенно новая («свободная») манера развертывания материала, позволяющая «автору» меняться в продолжение поэмы в зависимости от самого материала. «Автор - то эпический рассказчик, то иронический болтун, сам забывающий о чем идет речь (песнь V “Да впрочем дело не о том”, “Но полно, я болтаю вздор”). Это происходит оттого, что жанр поэмы оказался комбинированным в “младший эпос", в conte замешалась лирика (элегия, послание, а в картине боя - ода)» [Тынянов, 1969, с. 137]. Поэма перестала быть «легкой сказкой», на основе «младшего эпоса» вырос комбинированный жанр с использованием других, лирических жанров [Там же, с. 137]. Например, знаменитый «бой» в VI песне «Руслана и Людмилы» равным образом воспроизводит одическую интонацию повествования с частичным переходом в героический эпос:

И день настал. Толпы врагов

С зарею двинулись с холмов;

Неукротимые дружины,

Волнуясь, хлынули с равнины

И потекли к стене градской;

Во граде трубы загремели,

Бойцы сомкнулись, полетели

Навстречу рати удалой,

Сошлись - и заварился бой.

Бесстрофическая композиция «Руслана и Людмилы» не позволяла на слишком большом пространстве поэмы выдерживать один и тот же эмоциональный тон $^{2}$. При этих стиховых условиях была создана двойственная, двупланная окра-

\footnotetext{
${ }^{1}$ См. в «Проблеме стихотворного языка: «Слово не имеет одного определенного значения. Оно - хамелеон, в котором каждый раз возникают не только разные оттенки, но иногда и разные краски. Абстракция “слова”, собственно, является как бы кружком, заполняемым каждый раз по-новому в зависимости от того лексического строя, в который оно попадает, и от функций, которые несет каждая речевая стихия. Оно является как бы поперечным разрезом этих разных лексических и функциональных строев» [Тынянов, 1965, c. 77].

${ }^{2}$ Ср.: «Четырехстопный ямб, с которым связаны главные поэмы Пушкина, представлял ряд смысловых условий, важных для жанра поэмы. Прежде всего, с ним не была связана определенная жанровая окраска. <..> Эта неопределенная жанровая функция метра освобождала Пушкина от ассоциаций с готовыми эпическими жанрами как старшими, так
} 
ска повествовательной линии. Лирическое напряжение «боя» могло быть сломано комической сюжетной ситуацией, связанной с Русланом, в которой существенно проявлялись поведенческие стереотипы сказочного жанра:

\author{
Бегут нестройными толпами \\ И видят: в поле меж врагами, \\ Блистая в латах, как в огне, \\ Чудесный воин на коне \\ Грозой несется, колет, рубит, \\ В ревущий рог, летая, трубит... \\ То был Руслан. Как Божий гром, \\ Наш витязь пал на басурмана; \\ Он рыщет с карлой за седлом \\ Среди испуганного стана. \\ Где ни просвищет грозный меч, \\ Где конь сердитый ни промчится, \\ Везде главы слетают с плеч \\ И с воплем строй на строй валится.
}

Смешение интонационно-эмоциональных планов наблюдается в элегическом отступлении V песни поэмы («Я помню маленький лужок»), в котором Пушкин использовал «разговорную паузу», обозначив ее многоточием, для того чтобы внести в стих «личную» интонацию послания:

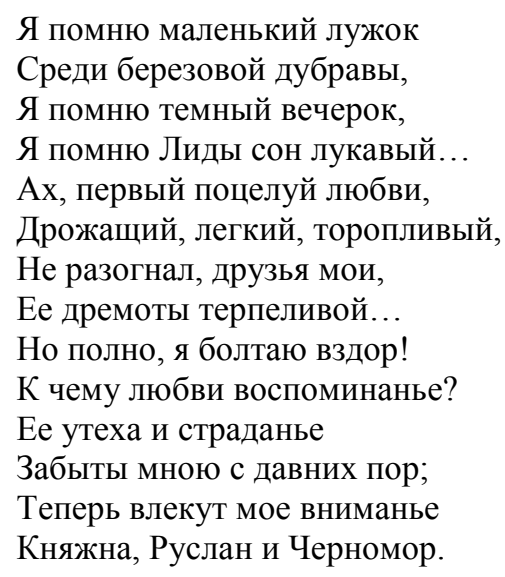

Переменность материала влекла за собою отказ от сложной, развитой фабуль: «В результате комбинированного жанра "Руслана и Людмилы” была нащупана эпическая пружина большой сложности. В этой поэме обнаружились как бы два центра “интереса”, динамики: 1) фабульный, 2) внефабульный. Сила отступлений была в переключении из плана в план. Выступало значение этих “отступлений” не как самих по себе, не статическое, а значение их энергетическое: переключение, перенесение из одного плана в другой, само по себе двигало» [Тынянов, 1969, с. 138]. Это переключение (так называемые «отступления») явилось главным сюжетным средством поэмы и основным регулятором трактовки «свободного героя»: «При этой внефабульной динамике сами герои оказались переключаемыми из плана в план. Осталось, в сущности, только амплуа героев, на которые нагружается разнообразный материал» [Там же, с. 139]. В «Руслане

и младшими и давала возможность легкого перехода от повествования в собственном смысле к лирике» [Тынянов, 1969, с. 136, 137]. 
и Людмиле» Пушкин использует прием (так называемые «гомерические» сравнения), который показывает «широту захвата» героем фабульного материала, а также его невесомость. Известное сравнение похищения Людмилы с тем, как похищает коршун у петуха курицу, или пушкинское описание страданий головы в сопоставлении с переживаниями современного «питомца Мельпомены»:

От удивленья, боли, гнева,

В минуту дерзости лишась,

На князя голова глядела,

Железо грызла и бледнела,

В спокойном духе горячась,

Так иногда средь нашей сцены

Плохой питомец Мельпомены,

Внезапным свистом оглушен,

Уж ничего не видит он,

Бледнеет, ролю забывает,

Дрожит, поникнув головой,

И, заикаясь, умолкает

Перед насмешливой толпой, -

возможны были лишь при условии внесюжетного построения, при котором герои являлись только «точкой пересечения фабульных линий». В «Руслане и Людмиле» впервые была сделана заявка на изменение значения героя в противоположность описанию «характера», мотивированного реальной действительностью.

«Евгений Онегин», так же как и «Руслан и Людмила», является смешанным комбинированным жанром. Обычные сюжетные схемы романов при вводе в стиховой механизм приобретали значение композиционной игры, провоцирующей смену стилевых и эмоциональных планов:

Господский дом уединенный,

Горой от ветров огражденный,

Стоял над речкою. Вдали

Пред ним пестрели и цвели

Луга и нивы золотые,

Мелькали селы; здесь и там

Стада бродили по лугам,

И сени расширял густые

Огромный, запущенный сад,

Приют задумчивых дриад (II, 1).

Он в том покое поселился,

Где деревенский старожил

Лет сорок с ключницей бранился,

В окно смотрел и мух давил.

Все было просто: пол дубовый,

Два шкафа, стол, диван пуховый,

Нигде ни пятнышка чернил (II, 3).

В «Евгении Онегине» проявились рудименты сказки (см., например, следующий стиховой отрезок из сна Татьяны):

Не видя тут ни капли толку,

Глядит она тихонько в щелку,

И что же видит?.. за столом 
Сидят чудовища кругом:

Один в рогах с собачьей мордой, Другой с петушьей головой, Здесь ведьма с козьей бородой, Тут остов чопорный и гордый, Там карла с хвостиком, а вот Полужуравль и полукот $(\mathrm{V}, 16)$.

Еще страшней, еще чуднее:

Вот рак верхом на пауке,

Вот череп на гусиной шее

Вертится в красном колпаке,

Вот мельница вприсядку пляшет

И крыльями трещит и машет;

Лай, хохот, пенье, свист и хлоп,

Людская молвь и конский топ! $(\mathrm{V}, 17)$.

Пушкинский стихотворный роман, как и первая поэма-сказка «Руслан и Людмила», представлял собой комбинированный, смешанный, новый, без готового «названия» жанр, воспринимаемый критикой с точки зрения «выпада из системы» [Тынянов, 1977, с. 192-193] (ср.: «Руслан и Людмила» долгое время была не-жанром, ее отказывались считать жанром люди, воспитанные на эпопее, так же как не-жанром был «Евгений Онегин», с которым трудно было примириться после «Руслана и Людмилы»). «Раздробленная» конструкция «Евгения Онегина», основанная на двух «центрах динамики», повторяла ту же борьбу фабульного и внефабульного начала, что и «Руслан и Людмила». В результате энергетического переключения из плана в план, из одного тона в другой была создана большая стиховая форма. В итоге, динамизм жанра, определивший развитие художественной системы Пушкина, стал исходной предпосылкой для окончательного канонизирования тыняновской теории литературной эволюции: «Жанр неузнаваем, все же в нем сохранилось нечто достаточное для того, чтобы и эта "не-поэма" была поэмой. И это достаточное - не в “основных", не в “крупных" отличительных чертах жанра, а во второстепенных, в тех, которые как бы сами собою подразумеваются и как будто жанра вовсе не характеризуют. $<\ldots>$ Но тогда становится ясным, что давать статическое определение жанра, которое покрывало бы все явления жанра, невозможно: жанр смещзается: перед нами ломаная линия, а не прямая линия его эволюции» [Там же, с. 256].

«Вторичным» признаком пушкинского жанра в данном случае будет выступать новая строфическая форма - онегинская строфа, обладающая исключительной динамичностью, конструкция которой настолько выделяется среди явлений предшествующей литературы, что выпадает из поля зрения при «статическом» рассмотрении литературного факта. В статье «Пушкин» Тынянов зафиксировал «проблему семантики метра» и указал на одическое происхождение онегинской строфы. «Важность метра в жанровом отношении... не подлежит сомнению. <..> В том или ином метре ... есть целый ряд смысловых условий... Так, известные формы ямба неминуемо вызывают окраску эпопеи, оды и т. д.». «Строфа "Евгения Онегина" есть в данном случае открытие Пушкина и является столь же законченной и полной смысловых условий строфической формой, как октава. Все дело было здесь в разнообразном объединении в стиховое целое малых стиховых единств... и, в особенности, в перекличке сходных групп». «Разнообразие по- 
строения строфы было культивируемо в оде и там же было нащупано значение парных групп...» [Тынянов, 1969, с. 136, 157, 158]. ${ }^{1}$

Разнообразя одическую строфу, в которой культивируемым было значение парного конца и вершины, Пушкин вносит другие виды объединений в «стиховое целое малых стиховых единств»: первая перекрестно рифмующаяся малая строфа, являющаяся как бы стиховым тезисом, противополагается второй малой строфе с опоясываюшими рифмами - стиховому антитезису. Логическое противопоставление стихового тезиса и антитезиса давало возможность переключать из одного тона в другой на пространстве одной строфы [Тынянов, 1969, с. 158], регулируя интонационные сломы стиховой речи. Следующим фактором, меняющим в эмоциональном отношении строфу, выступает перекличка двух групп с мужскими рифмами (7-8 стих и два конечных стиха). Значение подобных групп было в том, что ослабленность напряжения в конце строфы, созданная этой перекличкой, позволяла применять ее с «диаметрально-противоположными целями, то в виде “высокого” конца, то в виде комического» (ср., например, следующие строфы пушкинского романа):

Там Озеров невольны дани Народных слез, рукоплесканий

С младой Семеновой делил;

Там наш Катенин воскресил Корнеля гений величавый;

Там вывел колкий Шаховской

Своих комедий шумный рой,

Там и Дидло венчался славой,

Там, там под сению кулис

Младые дни мои неслись (I, 18).

А ты, младое вдохновенье, Волнуй мое воображенье,

Не дай остыть душе поэта, Ожесточиться, очерстветь, И наконец окаменеть

В мертвящем упоенье света,

В сем омуте, где с вами я

Купаюсь, милые друзья! (VI, 46).

Проясним некоторые положения Тынянова на примере одной из строф пушкинского стихотворного романа:

1. Почтенный замок был построен,

2. Как замки строиться должны:

3. Отменно прочен и спокоен

4. Во вкусе умной старины.

5. Везде высокие покои,

6. В гостиной штофные обои,

7. Царей портреты на стенах,

8. И печи в пестрых изразцах.

9. Все это ныне обветшало,

10. Не знаю, право, почему;

\footnotetext{
${ }^{1}$ О семантике метрических форм в связи с идеями Тынянова см.: [Гаспаров, 1984,
} c. 106-113]. 
11. Да, впрочем, другу моему

12. В том нужды было очень мало,

13. Затем, что он равно зевал

14. Средь модных и старинных зал (II, 2).

Колебание стиховой интонации является следствием двойственной природы онегинской строфы. Интонационное выделение лирической вершины (первая перекрестно рифмующаяся малая строфа) подчеркивается одическими рудиментами новой строфической формы, связанными с ее происхождением. При длительной выдержке одного тона они окрасили бы стиховую речь в оду. Для смысловой организации всей строфы важным условием представляется тот факт, что только один ритмический период построен по принципу перекрестных рифм. В тыняновской семантике стиха смысл двух слов, фонически сближенных, взаимно пересекается. Активизация значения рифмующихся слов определяется фактором их «стиховой близости» (деформация смысла в стихах с перекрестными рифмами будет более слаба, чем в стихах с опоясывающими или парными) [Тынянов, 1977, с. 77]. В этом случае слабая деформированность фонических элементов относительно смысла преображается в явления, имеющие конкретную семантическую ощутимость в прозе. Так, первая перекрестно рифмующаяся малая строфа приобретает значимость чисто семантическую, воспринимается как известный сюжетный пункт.

Организационная структура строфы, состоящая из двух частей (8+6 стихов), провоцирует авторское отступление с изменением интонационно-лексического плана. Лирическое повествование, начиная с 9-го стиха, во фразеологическом отношении опирается на прозу. Важность для Пушкина «большой стиховой формы» подчеркнута энергетическим моментом переключения из одного плана в другой. В тыняновской теории литературной эволюции «онегинская строфа» репрезентирует один из основных законов «динамизма формы», утверждающий «наиболее широкое колебание ... в соотношении конструктивного принципа и материала. $<\ldots>$ Вся суть “новой формы” в новом принципе конструкции, в новом использовании отношения конструктивного фактора и факторов подчиненных - материала. Взаимодействие конструктивного фактора и материала должно все время разнообразиться, колебаться, видоизменяться, чтобы быть динамичным» [Там же, c. 262].

Эволюционный путь Пушкина в трактовке Тынянова представляет собой процесс самодвижущейся формы, вершинной точкой которого могло бы стать беспредметное искусство. Выстраивая эволюцию пушкинского стихового эпоса как эволюичю форм, Тынянов уводил литературный текст за пределы истории литературы, где властвовала категория художника, в сторону искусства внеличностного и вневременного. Формалистические установки Тынянова исключали, с одной стороны, продуктивность психологического подхода к описанию литературных явлений; с другой - создавали необходимые условия для построения поэтики, т. е. теоретически обоснованной модели литературной науки.

\section{Литература}

Гаспаров М.Л. Тынянов и проблема семантики метра // Тыняновский сборник. Первые Тыняновские чтения. Рига, 1984. С. 106-113.

Томашевский Б.В. Пушкин: Современные проблемы историколитературного изучения. Л., 1925.

Тынянов Ю.Н. Проблема стихотворного языка. Статьи. М., 1965.

Тынянов Ю.Н. Пушкин и его современники. М., 1969.

Тынянов Ю.Н. Поэтика. История литературы. Кино. М., 1977. 